\title{
Learning from collaborative research on sustainably managing fresh water: implications for ethical research-practice engagement
}

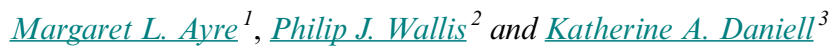

\begin{abstract}
Since the mid-2000s, there has been increasing recognition of the promise of collaborative research and management for addressing complex issues in sustainably managing fresh water. A large variety of collaborative freshwater research and management processes is now evident around the world. However, how collective knowledge development, coproduction, or cocreation is carried out in an ethical manner is less well known. From the literature and our experiences as applied, transdisciplinary researchers and natural resource management practitioners, we seek to describe and explore these aspects of empirical cases of collaborative freshwater research and management. Drawing on cases from Indigenous community-based natural resource management in northern Australia, flood and drought risk management in Bulgaria, water management and climate change adaptation in the Pacific, and regional catchment and estuary management in Victoria and New South Wales in Australia, we identify lessons to support improved collaborative sustainable freshwater management research and practice. Cocreation represents an emerging approach to participation and collaboration in freshwater management research-practice and can be seen to constitute four interlinked and iterative phases: coinitiation, codesign, coimplementation, and coevaluation. For freshwater researchers and managers and their collaborators, paying attention to these phases and the ethical dilemmas that arise within each phase will support the cocreation of more effective and ethical research-practice through: sensitizing collaborators to the need for reflexivity in research-practice, proposing action research codesign as a method for managing emergent questions and outcomes, and supporting more equitable outcomes for collaborators through an emphasis on coevaluation and collaborative articulation of the links between research outputs and practice outcomes.
\end{abstract}

Key Words: cocreation; collaboration; ethical research practice; freshwater management

\section{INTRODUCTION}

With a growing trend toward collaborative approaches for managing freshwater resources, researchers of all kinds have become involved in a range of collective and participatory processes. Their roles range from documenters and evaluators to instigators, designers, model providers, facilitators, and active stakeholders of collective natural resources management, including freshwater management. This continuous growth in researcher-stakeholder interaction in freshwater management has led to substantial bodies of literature distributed across and between academic disciplines. This literature addresses methods related to, and the results of, such interactions, and the collective knowledge and action that arises from them. Attempts to foster changes in freshwater management and stakeholder actions as a result of the collective processes include, but are not limited to, literature about joint action, participatory and transdisciplinary research (e.g., Barreteau et al. 2010), coinquiry (e.g., Heron and Reason 2001, Mackay et al. 2014), coproduction (e.g., Pohl et al. 2010, Dilling and Lemos 2011, Brugnach and Ingram 2012), systemic intervention and cocreation (e.g., Midgley 2000; Midgley, unpublished manuscript, http://dx.doi.org/10.13140/

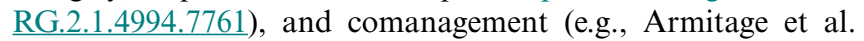
2011, Plummer et al. 2012). There is also a significant body of literature on ethics in water governance internationally (e.g., Groenfeldt and Schmidt 2013, Schmidt and Peppard 2014), to which we seek to add with this current work.

The ability of researchers to engage effectively in collaborative approaches in freshwater management is arguably underpinned by a range of skills and knowledge related to methods for effectively interacting with a range of other people, often with different cultures, beliefs, knowledge, practices, and values, and methods related to the substantive freshwater management topic of interest (termed "coproductive capacities and practices" by Wyborn 2015). However, this ability is also linked to individual and institutional imperatives and constraints. Specifically, because of researchers' values and morals, elements that are key to shaping individuals' decision-making practices, in some cases, they may feel inclined to seek to make an immediate impact and difference on issues or working toward their social goals such as environmentally sustainable water management, promoting lowimpact development, or enhancing a particular form of social or environmental justice (see, for example, the diversity of approaches in the cases of Lukasiewicz et al. 2017). However, in other cases they may not see themselves as directly participating in responses to the issues at hand, but rather as observers of the action. The former approach can be realized through undertaking research-related work in collaboration with stakeholders. Such "engaged research" aims to respond to challenges faced by stakeholders in their everyday lives and work. The institutional rules of the organizations within which researchers work may also dictate or guide the way in which such stakeholder engagement or human participation in research ought to occur. It is through embedding reflective practices in research collaborations that the importance of different ethics or ethical practices in engaging in collective working arrangements, and ideally collaboration, comes to the fore.

While we do not suggest that unethical practices necessarily take place, here, we seek to explore the idea that collective work in the space between research and stakeholder decision making and action in freshwater management may sometimes be undertaken without careful or explicit consideration of ethical practice. We also explore the idea that, even when explicit consideration is

${ }^{1}$ Faculty of Veterinary and Agricultural Sciences, University of Melbourne, ${ }^{2}$ Victorian Catchment Management Council, Victoria, Australia, ${ }^{3}$ Fenner School of Environment and Society, Australian National University 
made, the practical realities of working with others mean that researchers must face challenging or uncomfortable ethical dilemmas from certain institutional and social perspectives. Although much work has been undertaken on ethics related to natural resources management, including specifically on water governance, relatively less work has been undertaken on the ethics related to the organization and participation of researchers in collective working arrangements with stakeholders for participatory natural resources management, and water management more specifically (Daniell 2012). We thus seek to increase understanding and discussion on the ethics of the collective organization of participatory processes for freshwater management. We aim to address the following questions. What typical ethical issues arise for researchers and practitioners in the organization of participatory processes for sustainable freshwater management with stakeholders? Why do these issues arise? What might researchers and practitioners do to improve ethical practice in such situations?

Here, we seek to address these questions across all aspects of cocreation of collaborative freshwater management processes, including phases of coinitiation, codesign, coimplementation, and coevaluation. As Daniell et al. (2010) and Daniell (2012) highlight, the prefix "co-" relates to activities undertaken together with others, providing the example of coengineering as the collective organization of participatory processes. The "co-" may not always represent collaboration, but could equally represent conflict or cooperation. A range of "co-" approaches are reported in the literature, although not all examples of collective processes are labelled with the prefix.

As an example, in his discussion on systemic cocreation in natural resources management contexts, Gerald Midgley (unpublished manuscript, http://dx.doi.org/10.13140/RG.2.1.4994.7761) notes how all of his previous work on systemic intervention with stakeholders could have used the "cocreation" or other "co-" labels, although it is something he has not done until recently. $\mathrm{He}$ now defines cocreation as a process in which "parts (perspectives) are engaged in a whole (dialogue) that generates an emergent property (synergistic innovation) that is meaningful in context (it is useful)" (Midgley, unpublished manuscript, http://dx.doi. org/10.13140/RG.2.1.4994.7761). He also discusses how such a process, if it is to be successful, requires avoidance of destructive conflicts, as well as clear attention to context to involve the "right" people and issues and to avoid harmful side-effects of intervention. It should be noted, however, that deciding who are the "right" people and what are the "right" issues to address is a question of ethics because it involves making judgements. Similarly, considering what is "destructive" or otherwise is an ethical matter because such judgements are based in particular ontological and epistemological positions. Such processes thus require informed, careful, and responsible management in which ethical practices are clearly reflected on and planned for, including the use of the most appropriate methods for building systemic awareness among potential collaborators.

\section{Background to ethics in collaborative research-practice}

Focusing specifically on collaborative processes for sustainably managing and researching fresh water, Groenfeldt and Schmidt (2013:3) claim, "Attention to ethics has largely been absent in discussions of water governance." However, there have been work and discussions within the discipline of water governance on ethics, including those in The Water Ethics Network (http:// waterethics.org/) and by Lach et al. (2005), Whitely et al. (2008), Daniell et al. (2009), and Groenfeldt (2013). Schmidt and Peppard (2014), for example, examined the role of ethics in participatory water planning, including the dilemmas arising in and between the application of different participants' ethical frameworks in participatory settings.

Other scholars such as Doorn (2013) have identified an outstanding need to pay attention to ethics in water governance, and they call for the increased involvement of applied ethicists and political philosophers in determining processes for ensuring ethical outcomes from stakeholder engagement in water management. Groenfeldt and Schmidt (2013) also emphasize attention to ethics in water management because it "supports the task of finding governance arrangements that not only recognize multiple values, but... also provide[s] a framework for reasoning about alternate options." However, we also emphasize here the need for the conduct of responsible research-practice to realize the ethical outcomes of cocreating such alternate outcomes. This requires us to both attend to our own practices as reflective practitioners (Schön 1984) and to understand better what is required in planning for and conducting research-practice collaborations. Many water governance authors involved in reflective practice describe lessons and responsibilities for effective collaborative processes (e.g., Seligman et al. 1994, Ison et al. 2004, 2007, Pohl et al. 2010, von Korff et al. 2010, 2012, Allen et al. 2011, Fenemor et al. 2011, Hare 2011, Kilvington et al. 2011a,b, Camkin 2016), but here, we seek to understand the ethics that lead to these types of positive and collaborative research-practice.

Here, when we write about whether practices are ethical, we are questioning the "rightness" or "goodness" of action. Such ethics are defined by personal values, reasoning, and feelings, or by societal norms and rules. However, in collaborative practice, decisions and practices are likely to be based on a range of different perspectives of "right" or "good" (Daniell et al. 2009). In this way, prevailing values and attitudes of diverse people affect assessments of fairness in water policy and management, including collaborative research to support sustainable futures (see Syme et al. 2008). Our approach to ethics arises from a social constructivist epistemology (Becker 1986) that locates all meaning and human experience in networks (or systems) of diverse materials, symbols, and social arrangements (see Latour 1987, Addelson 1994). In this framing, the processes and outcomes of research-practice are achieved in the relations between diverse actors, both human and nonhuman (Shove and Walker 2010), in a given situation. This necessarily involves ethical researchpractice as one such process of collective activity. Therefore, ethical action is created in the interactions between people or institutions in particular times and places using particular material and symbolic resources. Evidence of ethical action emerges both in the process of doing research-practice and in the outcomes from this process.

Unpacking what is meant by "ethics" to explore dilemmas related to research-stakeholder interactions in freshwater management, Guillemin and Gillam (2004) consider "procedural ethics" (or what is also known as "professional ethics") as the processes 
involved in obtaining ethics approval from a committee and then following ethical protocols and guidelines in research, and they consider "ethics in practice" as the ways in which researchers actually engage with participants. They claim that the process of applying for procedural ethics approval does not necessarily contribute to ethical research practice, and they also emphasize that responsibility to engage in ethical practice falls on researchers and not on human research ethics committees. Some scholars argue that applying ethical review approaches developed for biomedical studies to qualitative social research can impede research or possibly heighten the risk to participants (De Vries et al. 2004). Other scholars have identified that in situations in which professional ethics (such as those involved in funding or research codes of practice) and community norms intersect such as in collaborative research, different values are at play, and therefore, ethical framings can be fraught and contested (see Pradhan and Meinzen-Dick 2003, Orlove and Caton 2010). Ellis (2007) adds a third dimension of "relational ethics" to Guillemin and Gillam's (2004) two categories, which draws attention to the interpersonal bonds formed between researchers and participants. This is particularly relevant in the context of long-term collaborative research partnerships, where the lines between researchers and participants can be blurred when the focus is on managing natural resources such as water.

For researcher-practitioners involved in collective efforts to manage freshwater resources sustainably, it is important to recognize that substantive goods and procedural goods have different implications for ethics in participatory processes (Schmidt 2014). Despite more theoretically democratic forms of research-practice being considered and applied in natural resources management over recent decades, the political context, including incumbent power structures, as well as the ontological and epistemological commitments of participants in researchpractice engagements, all affect the ethical frameworks that are both represented and generated within such processes. It is critical, therefore, to consider the questions: Who benefits and how? (from participation), and What is considered "ethical," by whom, and why?

Our purpose here is to consider how collaborative processes for sustainably managing and researching fresh water can be ethically designed and facilitated. We draw on cases from our own work and experiences of collaborative research and planning in different freshwater management contexts. We consider whether existing ethical research frameworks are fit-for-purpose in cocreation approaches, and we identify lessons for ethical cocreation practice in research and planning for sustainable freshwater management. We define ethical cocreation as the process of creating ethically just and responsible researchpractice collaborations involving researchers and expert practitioners in various "communities of practice" (Wenger 1998).

\section{METHODS}

As researcher-practitioners working in freshwater management contexts, our inquiry involves engaging in critical reflection on our experiences of collective work aimed at sustainably managing and researching fresh water. We are guided by systemic thinking and practice (Blackmore et al. 2007, Ison et al. 2007, Blackmore 2010, Ison 2010), recognizing that we learn from our engagement in ways other than independent and structured observational research. These ways include being positioned within the inquiry, acting with awareness of our own assumptions and values, and creating conditions that allow for the emergence of new insights and knowledge (Rubenstein et al. 2016).

The method we used for our inquiry was to apply a conceptual framework of cocreation in research-practice derived from previous empirical work in the domain of water governance (Daniell et al. 2010, Daniell 2012). Following and expanding on this work, this framework of cocreation in research practice (Table 1) for freshwater management consists of four main phases: (1) coinitiation, which involves activities associated with the beginning of a cooperative venture, whether new or a continuation of an existing initiative; (2) codesign, which focuses on decisions and collective activity on methodology and process; (3) coimplementation, where the design is enacted and the participatory processes facilitated; and (4) coevaluation, which involves assessing performance in some way. Each of these phases is characterized by different key elements, which constitute collaborative research-practice. These elements are the structures (e.g., protocols and working arrangements) and functions (e.g., roles and relationships) that enable ethical collaborations. We recognize, however, that not all research-practice situations involve all of the phases or elements of cocreation, and they do not necessarily take place in a linear fashion. For example, developmental evaluation is a form of coevaluation that takes place through all of these phases (Patton 2011), and codesign is likely to continue through the coimplementation phase to allow for ongoing participatory process adjustments (Daniell et al. 2010).

We used the framework of cocreation in research-practice for freshwater management to analyze eight cases of freshwater management and research (Table 2). Example references for these cocreation phases are presented in Table 2, although further references for all of the phases are also available in Daniell et al. (2010) and Daniell (2012). We applied the framework to each of the cases to explore where and how ethics-relevant researchpractice was occurring and what the outcomes were, as well as what ethical challenges arose and how they were addressed. The criteria for selection of the cases were threefold: (1) the case demonstrated at least two of the phases of cocreation in researchpractice; (2) the cases represented a range of scales of researchpractice activity, including local, regional or catchment, national, and transnational scales; and (3) we had some detailed personal experience of the conduct of the research-practice collaboration. In applying these selection criteria, we recognize that these cases are neither exhaustive nor "ideal" examples of cocreation in ethical research-practice. We also recognize that we had different roles in each case, and acknowledge that, by virtue of these particular roles, we may have different perspectives on and narratives of collaboration from those of the other participants.

We next present evidence from the eight cases of research-practice in which we have been active contributors. We then discuss the implications of these considerations for doing ethical researchpractice in freshwater management.

\section{RESULTS}

Our results are drawn from several real cases of collaboration in water governance in which we have been involved as researcher- 
Table 1. Analytical framework for cocreation in research-practice for freshwater governance and management.

\begin{tabular}{|c|c|c|}
\hline $\begin{array}{l}\text { Phase of cocreation in } \\
\text { research-practice }\end{array}$ & Key process elements & $\begin{array}{l}\text { Relevant literature on governance and collaboration related } \\
\text { to freshwater management }\end{array}$ \\
\hline $\begin{array}{l}\text { Coinitiation: roles, } \\
\text { relationships, and processes for } \\
\text { working together are } \\
\text { negotiated }\end{array}$ & $\begin{array}{l}\text { - All participants are involved in setting joint objectives and } \\
\text { outcomes for the collaboration } \\
\text { - Formal and informal agreements and frameworks are } \\
\text { negotiated to guide the collaboration } \\
\text { - Project governance is established and all participants' } \\
\text { interests and knowledge are represented }\end{array}$ & $\begin{array}{l}\text { Setting ground rules for interaction in collobarations: } \\
\text { Mostert (2007), Wiering et al. (2010); utility of integrated } \\
\text { frameworks to support participatory freshwater research-- } \\
\text { practice: Pahl-Wostl and Kranz (2010), Ayre and Nettle } \\
\text { (2015) }\end{array}$ \\
\hline $\begin{array}{l}\text { Codesign: activities and } \\
\text { working procedures are } \\
\text { identified and criteria for } \\
\text { success are negotiated }\end{array}$ & $\begin{array}{l}\text { - Adaptive plan for implementation of agreed-uopn project } \\
\text { activities is negotiated among participants } \\
\text { - Roles and responsibilities for delivering project objectives } \\
\text { are agreed upon } \\
\text { - Resources are allocated to project objectives and activities } \\
\text { to meet those objectives }\end{array}$ & $\begin{array}{l}\text { Roles in participatory freshwater management initiatives: } \\
\text { Creighton (2005); designing learning systems for water } \\
\text { management: Collins et al. (2009); codesign of participatory } \\
\text { water management processeson: Von Korff et al. (2010) }\end{array}$ \\
\hline $\begin{array}{l}\text { Coimplementation: research-- } \\
\text { practice activities are } \\
\text { undertaken with participants } \\
\text { acting together to achieve joint } \\
\text { outcomes }\end{array}$ & $\begin{array}{l}\text { - Joint project objectives are pursued through joint activities } \\
\text { - Leadership and facilitation of joint work programs is } \\
\text { important } \\
\text { - All participants contribute to and have ownership of } \\
\text { research-practice outcomes }\end{array}$ & $\begin{array}{l}\text { Role of negotiation and discourse in cooperation for cross- } \\
\text { regional water management outcomes: Wiering et al. (2010); } \\
\text { learning in groups (or social learning) in adaptive } \\
\text { comanagement of natural resources: Berkes (2009); } \\
\text { leadership and teamwork in coimplementation in water } \\
\text { management: Daniell (2012); frameworks to understand and } \\
\text { manage social processes for integrated catchment } \\
\text { management: Kilvington et al. }(2011 a)\end{array}$ \\
\hline Coevaluation & $\begin{array}{l}\text { - Participants agree on joint criteria and metrics for success in } \\
\text { collaboration } \\
\text { - Progress toward joint milestones and project objectives is } \\
\text { monitored through participatory methods } \\
\text { - The narrative of project achievements and challenges is } \\
\text { negotiated and produced jointly }\end{array}$ & $\begin{array}{l}\text { Action research as a research-practice approach involving } \\
\text { participatory evaluation: Carr and Kemmis (1986); } \\
\text { researcher-practitioner dialogue on evaluation of public } \\
\text { involvement in water resources planning: Syme and Sadler } \\
\text { (1994); joint success criteria for integration in research as a } \\
\text { basis for coevaluation: Ayre and Nettle (2015); framework } \\
\text { for monitoring and evaluating participatory planning } \\
\text { processes: Hassenforder et al. (2016) }\end{array}$ \\
\hline
\end{tabular}

participants. We summarize evidence from the cases (Table 1) and reflect on the particular ethical issues involved in four phases of cocreation in research-practice. We do not draw exhaustively on each case cited, all of which contain multiple examples of situations in which ethics in cocreation are demonstrable and relevant; rather, we seek to highlight key examples of ethics in cocreation from across the different cases.

\section{Coinitiation}

In the coinitiation phase of projects in freshwater management research-practice, participants, including social researchers such as ourselves, are ideally all involved in setting joint objectives and goals for the collaboration. However, from our experiences, coinitiation is not yet rigorously applied in practice. It has been noted that in the water industry in Australia, for example, cultural and social researchers are reportedly excluded from early phases of projects because of a positivist stance on knowledge production that privileges technical science disciplines over the social sciences (Sofoulis 2013), although there are notable exceptions.

We have experience of coinitiation from a research-practice collaboration with an Indigenous community in remote Australia (case 2). The aim of this collaboration was to develop participatory planning methods for engaging local Indigenous community members and local stakeholder organizations, including Indigenous community groups, in identifying and representing their values, interests, and objectives for freshwater management. This collaboration was formalized during the coinitiation phase through a memorandum of understanding (MoU) between the relevant Indigenous land council and its land and sea management section, the government department, and the research institution involved. In this way, all relevant project partners were part of coinitiation, although this does not necessarily guarantee that power relations are appropriately defined or managed. The MoU was a useful institutional arrangement for supporting coinitiation and negotiating how important ethical issues would be addressed between different organizations, such as data ownership, access to indigenous knowledge, and protocols for consent for data release and publication. Procedural ethics were also sought and approved through the lead research organization.

A contrasting experience arose in case 7 in a project that brought together a range of biophysical and social researchers, technical advisors, and policy makers from different European and Pacific countries to understand challenges and propose research projects, policies, and ways forward in water management in the context of global climate change. In this case, coinitiation was only conducted by a stakeholder group and local researchers in one country, and therefore, a subset of all project participants. However, the subsequent design of project activities and their implementation and evaluation were all collaboratively conducted across a large team of international and local participants, enabled by a mix of online and face-to-face 
Table 2. Cases used to study collaboration in sustainable freshwater management research-practice.

\begin{tabular}{llll}
\hline \hline Case & Title & Funders & Organizations involved \\
\hline 1 & Farms, Rivers and Markets & National Water Commission, Uniwater, & University of Melbourne, Monash \\
& & University of Melbourne, State & University, MDFRC, Latrobe \\
& & Government of Victoria & University, Goulburn-Murray Water, \\
& & North Centre Catchment Management \\
& & & Authority, Murray Darling Basin \\
& & Authority
\end{tabular}

Cocreation phases:

- Coinitiation: senior academics at the University of Melbourne, Monash University, and MDFRC in discussion with government and industry partners; upon receipt of funding, researchers were recruited, and the final team included 54 people across four research institutions

- Codesign: senior University of Melbourne academics who wrote the funding proposal, which included a framework for transdisciplinary research (Ayre and Nettle 2015); procedural ethics were obtained by social scientists to undertake an inquiry into integration in catchment management research; design elements for community and industry engagement included a Farmer Reference Group and a Catchment Management Reference Group with representatives from key agricultural industry professions (dairy, cropping, and horticulture) and water management and policy arenas (e.g., irrigation systems, catchment management, and federal and state governments), respectively

- Coimplementation: researchers at various sites, including University of Melbourne, Latrobe University, and Monash University in Melbourne, and MDFRC in Albury; field trials and workshops were established at the University of Melbourne campus at Dookie, and field trials occurred on commercial farms in the Goulburn Valley in northeast Victoria; researchers worked in teams to address joint research questions and project milestones; new joint research questions emerged as the project was implemented and led to new knowledge for managing water for the dual purpose of irrigation and environmental benefit (Farquharson et al. 2017) - Coevaluation: through an action research process led by social scientists, a set of participatory evaluation principles and criteria were codeveloped by researchers in the project and used to coevaluate the transdisciplinary research process

2 Tiwi Islands Water Planning

National Water Commission and TRaCK

\author{
Tiwi Land Council, Northern Territory Hoverman and Ayre (2012) \\ Government, CSIRO ${ }^{\ddagger}$, Griffith \\ University
}

Cocreation phases:

- Coinitiation: the three key research partners; two agreements were negotiated and signed by parties: a Memorandum of Understanding between the Northern Territory Government and the Tiwi Land Council and an Environmental Research Access Agreement between CSIRO and the Tiwi Land Council

- Codesign: adopted an action research methodology (Mackenzie et al. 2012) such that all research activities were codesigned with key participants as members of the Tiwi Island Water Planning Team (WPT; established in the project); aimed to engage the diversity of Tiwi stakeholders in water management through community workshops, participatory mapping, a physical three-dimensional groundwater model, and "visits-to-country" (see Hoverman and Ayre 2012)

- Coimplementation: as per codesign of research activities, all activities were also coimplemented through a collaboration between members of the WPT, with researchers (CSIRO, Griffith University), the water planner (Northern Territory Government), and water managers (Tiwi Land Council and Tiwi landowners and community members)

- Coevaluation: members of the WPT and project participants at workshops (through evaluative discussions and formal feedback forms); Tiwi Land Rangers also undertook a formal evaluation of all participatory planning tools trialled with other members of the WPT (see Hoverman and Ayre 2012)
Managing change in dairy regions: the
Dairy Australia, Murray Dairy
University of Melbourne, Dairy
Ayre and Nettle (2017)
G-MW Connections Project
Australia, Murray Dairy

- Coinitiation: researchers and the industry and funding body (Dairy Australia) as a result of a prior research collaboration; a project steering committee of dairy and water industry experts and farmers was set up, and a terms of reference for this committee was negotiated and agreed upon

- Codesign: lead researchers with the project steering committee; included iterative development of the research plan, which was discussed at six monthly steering committee meetings; steering committee members were key participants in a project action research intervention to trial a process for assessing a major regional change challenge faced by the dairy industry in Victoria, the modernization of the Goulburn Murray Irrigation District

- Coimplementation: researchers and steering committee members who were active participants in the regional resilience assessment process

- Coevaluation: project participants were engaged in ongoing evaluation through reflection at regular steering committee meetings, interviews with participants, and written evaluation of project activities; the published journal article from this research was authored by the researchers

4 Climate change impacts and adaptation Australian Government planning for the Southern Slopes NRM

University of Tasmania, Monash

Bosomworth et al. (2017), Wallis et al. regions

Cocreation phases:

University, RMIT University, 9 regional (2017)

NRM agencies, 3 state NRM agencie

- Coinitiation: two separate streams of work were funded, one for NRM agencies to prepare for climate change across a range of assets (including waterways) and another for consortia of researchers and policy teams to support planning across multiple NRM agencies. Some coinitiation occurred within the consortia in preparing the bid; however, little contact was made between the two streams in this phase

- Codesign: following receipt of funding, a research partnership was developed to codesign techniques, boundary objects, and approaches for planning for climate change - Coimplementation: an "adaptation pathways" planning approach was jointly developed and implemented through cofacilitation in different regional contexts; climate planning information needs were negotiated and developed through an interactive online portal

- Coevaluation: took place at both the project level (internally) and program level (externally); a developmental evaluation approach was used throughout the life of the research partnership

$5 \quad$ Water Governance Research Initiative
National Climate Change Adaptation Research Facility, Australian Government
Monash University; University of

Melbourne; 150 active participants fron

research, government, and industry
Wallis et al. (2012), Patterson et al. (2013), Rubenstein et al. (2016)

Cocreation phases:

- Coinitiation: funded to advance collaboration on climate change research among freshwater governance researchers and practitioners; network conveners established a reference group to build the network and ensure representation from a wide range of geographies and academic disciplines

- Codesign: based on systemic inquiry, i.e., a facilitated process using systems techniques to enable ideas to emerge around issues of concern; the reference group contributed to the initial design of network activities

- Coimplementation: participants were actively involved as contributors and initiators of all research-practice activities; feedback from participants was used to guide network activities (e.g., demand for an early career researcher-focused workshop)

- Coevaluation: conducted through interactive workshops and three surveys of participants throughout the initiative 

Supporting flood and drought risk
management in Bulgaria's Upper Iskar
European Commission

Basin

Cocreation phases:

- Coinitiation: European Union project researchers in consultation with a Bulgarian stakeholder group

- Codesign: international and Bulgarian researchers together; there was also adaptive and ongoing codesign through the 1-yr process as stakeholder expectations and research team members changed

- Coimplementation: local Bulgarian professionals and students were trained by researchers as facilitators for implementating the process in the Bulgarian language; synthesis and supportive modeling and data presentation were undertaken by the combined international and Bulgarian team between workshops

- Coevaluation: coordinated by researchers and facilitators, with all stakeholder participants and facilitators participating in questionnaires, interviews, and group debriefing sessions

\section{Developing Pacific-European \\ European Commission and French} cooperation in water and climate change Ministry of Foreign Affairs research and innovation
National policy makers and government Daniell et al. (2010), Ribarova et al. officials, regional stakeholders, affected (2011), Daniell (2012) citizens, businesses, nongovernmental organizations

Cocreation phases:

- Coinitiation: iterative because different phases and cases in different locations were commenced at different times; a couple of researchers drove this coinitiation with project team members and local stakeholders throughout most of this process

- Codesign: as above; some phases involved large numbers of stakeholders and researchers, whereas some were primarily driven by a few key researchers. After some challenges with implementation of the codesigned workshop methodology at the beginning of the first European project, a professional facilitator and participatory process designer (from a small/medium enterprise) was brought in to strengthen the codesign and coimplementation (e.g., through facilitator training and simulation of the participatory methods prior to their deployment)

- Coimplementation: facilitators were typically researchers or local stakeholders that had been trained to deploy the methods by researchers; synthesis activities were typically undertaken by the researchers

- Coevaluation: less systematic and more opportunistic because these were network development and scoping projects; primary methods were project team debriefs, workshop or event auditing evaluations, researcher notes and reflections

Cocreation phases:

g., oyster farmers, residents)

- Coinitiation: local government asked for research input; the researcher assisted the Hornsby Shire Council to develop the content of the tender proposal for consultants to develop the plan through a participatory project; an environmental consulting firm was employed as a result of this tender

- Codesign: local government officials, consultants, and researchers worked together to design a process of three workshops and external scientific and legislative reviews; there were numerous negotiations over changes of design direction throughout the process

- Coimplementation: workshops were facilitated and information for the was plan synthesized by the consultants and researcher; logistics organization was supported by the Council

- Coevaluation: carefully designed from the project outset and involved intervention research methods (experimental report writing, reflexive practice debriefings, workshop participant questionnaires), as well as an external evaluator using a protocol developed in collaboration with another international project for participatory evaluation, involving participant observation and interviews

Murray-Darling Freshwater Research Centre.

Commonwealth Scientific and Industrial Research Organisation.

Natural resources management.

interactions over a number of years. This case highlights that coinitiation by a small group can grow into the basis for an effective, broader collaboration, and that subsets of participants in a network could coinitiate within their own local situations. However, this does not guarantee that what is agreed locally by participants would necessarily be honoured by other networks within the international consortium. Hence, there is a challenge of having processes whereby ethical considerations agreed upon locally can be applied or renegotiated by others in times and places remote from the original coinitiation phase. For example, although the collaborative water management aspect of this case was only initiated by some researchers, it occurred within a research project framework with a clear contract and multiparty consortium agreement and mechanisms. Most of the interactions and research developments were considered as brokering, scoping, and auditing of current water governance practice and needs, so no procedural research ethics applications were undertaken (e.g., through European Commission or national protocols). However, it is possible that if some consortium members initiated such work in their own or other countries, research permits may have been required, such as in Vanuatu or the Cook Islands (see Forsyth 2014).

Our further experiences in freshwater management researchpractice settings include projects that aim to foster collaboration across different disciplines and institutions in regional catchment management within Australia (Daniell et al. 2010, Ayre and Nettle 2015, Bosomworth et al. 2017, Wallis et al. 2017). In such projects, there are multiple challenges and ethical dilemmas that arise from working across research disciplines such as science, engineering, and social research as well as between different research and government institutions. In the case of one project, initiation was arguably unclear to all participants because the funding proposal was put together by a team of senior academics who were remote from many of the researchers who eventually worked in the project. Whereas the project was initiated primarily as a science and engineering initiative, social science was embedded in the project to support and track knowledge integration (Ayre and 
Nettle 2015), including designating roles for supporting collaboration through reflexive action research processes. Although ethics approvals were gained for this social science inquiry into knowledge integration within the research team and with farmers and water managers, other research involving stakeholder groups in farming and water management as part of the project was not necessarily covered by these approvals. In another case (case 8), researchers were more core to the development of a tender for services (i.e., they helped the government official to write the tender for consultants who would be responsible for the implementation of the collaborative process), but they had no more than an oral agreement from parties, both the government and the selected consultants, about their involvement in the cocreation process. The researchers involved were instead self-funded, had their own external ethics approval on which the external parties were not present, and had to show that they would bring value to the proposed collaboration in order to maintain the legitimacy of their participation.

\section{Codesign}

From our experiences, there are a range of approaches and ethical issues that arise in the codesign phase in freshwater researchpractice collaborations. For example, case 2 was aimed at engaging Indigenous communities in water planning and was codesigned by a small project team comprising representatives from each of the partner organizations. This project team met regularly to deliberate and plan project activities and informally review progress. Ethics approvals were granted through the research institution involved; however, this did not necessarily cover all aspects of ethical codesign practice in the project. The Tiwi people have an exhaustive system of custodial rights and responsibilities that determines Tiwi land and water ownership. In this system, particular people have roles and responsibilities for managing particular water places; it was critical that this was embedded in the project codesign. Hence, as the project team iteratively engaged project participants and Tiwi water managers in an applied action research approach, they learned that ethical codesign must involve participatory methods for representing the full range of Tiwi interests, knowledge, and lawful jurisdiction over Tiwi water resources and places. Four methods were codeveloped to achieve this: participatory mapping of Tiwi water places and objectives for use and management, community workshops to engage the broader Tiwi community in the Tiwi water planning process, a physical model of the hydrological cycle to demonstrate and share Tiwi and western scientific knowledge of water dynamics in the landscape, and "visits-to-country" that involved senior traditional owners (as Tiwi Water Delegates) hosting visits of the water planning team at important Tiwi water places to identify values and objectives for water management. The visits-to-country method ensured that protocols for Tiwi water governance were upheld (Hoverman and Ayre 2012).

Alternatively, cases 6 and 7 aimed to achieve international and cross-jurisdictional collaboration on European water management in the context of climate change. Through the projects, including the codesign of participatory activities, participants sought to adhere to the European Union's FP7 Research and Innovation funding program guidelines because, at the time, there were only minimal requirements for human research of this nature (the ethics interests focused more on medical research rather than on social research). However, many researchers from the technical sciences were not really aware of what ethical concerns might even arise because of their unfamiliarity with participatory or social research. Some of the research participants had their own institutional or country codes of ethical conduct or ethics approval processes, but only $\mathrm{PhD}$-level researchers sought this to ensure their work would meet dissertation regulations. International privacy protection mechanisms such as the European Union Data Protection Directive (European Parliament 1995) limit cross-border flows of data to countries where privacy protections are deemed inadequate. However, exceptions apply where, for instance, unambiguous consent is given, which could be assumed for these projects. Despite the complexities and ambiguities about which data ought to be collected and shared, pragmatism typically took over so that codesign, drawing on lessons from earlier phases of coimplementation, could take place over the long distances and international borders. The trust and strong relationships that developed between project partners became the foundations for ensuring that behavior in codesign and other cocreation phases met the ethical standards and preferences of the people involved in setting the agreed research direction. For example, in case 6, these foundations meant that when there were challenges and opportunities for changing the direction of a water planning exercise to exclude part of the problem framing (to focus on just floods instead of floods and droughts), these changes could be relatively easily accommodated for some ethical reasons (e.g., stakeholder benefit from research), even if it went against some other ethical principles (e.g., research integrity; Daniell et al. 2009). The trust between the external researchers and lead local organizers was a big part of finally accepting the reframing proposition

In case 1 , where interdisciplinary collaboration was critical to achieving research outcomes for improved catchment management, the project design was substantively formalized in the contract deliverables for the project. However, there was also scope for emergent outcomes to be identified and pursued by the research team through the codesign phase. Codesign was enabled through an iterative series of group activities, led by the social researchers and involving interviews and workshops, to shape evolving research questions and joint work programs. This reflexive process within the interdisciplinary research team was documented and evaluated as part of an action research process that was covered by ethics approvals through the lead research institution. A similarly iterative process of codesign was undertaken in case 8 after the original design was formalized in the tender, with a range of ethical dilemmas being negotiated by project partners, including changes to which key stakeholders ought to be allowed to participate in the last phases of the participatory planning process (see Daniell et al. 2009, 2010).

\section{Coimplementation}

All of our experiences of research-practice collaboration in freshwater management have involved coimplementation, although it would be possible for initiatives to be designed without this phase (e.g., in behavioral studies, interventions might be coinitiated, codesigned, and coevaluated, but implemented on separate research subjects). Case 4 on climate change planning focused on the coproduction of project outputs, resulting from an emphasis on capacity building of practitioners beyond the life of the project (Bosomworth et al. 2017, Wallis et al. 2017). The 
main ethical consideration was the ownership of codesign and coimplementation processes and coproduced outputs by both researchers and practitioners. This was achieved through iterative negotiation of expectations and rigorous project management to ensure timeliness, which meant that outputs were both academically legitimate and salient to the practice context.

In case 5, coimplementation was led by the project team but involved government water planners and community collaborators to support the participation of a broad range of water stakeholders, including key individuals with authority for water management, community members, and their organizations. This case demonstrated a developmental approach to both design and implementation through the use of systemic inquiry (Ison et al. 2015). Participants helped shape the format and direction of activities. For national-scale, open-invitation initiatives of this nature, balancing participation from a diversity of groups can be an ethical challenge because they tend to attract mainly salaried professionals. To rebalance participation, funding was provided in the form of travel support to enable attendance at events by remote and regional participants, as well as early career researchers.

In cases 6 and 7, the distributed approach to research-practice collaboration in semiautonomous local teams meant that crossproject communication, including to deal with ethical dilemmas such as data sharing and use, was a real issue that could only be resolved during face-to-face meetings (and considerable travel expense). However, this distributed system also provided an opportunity for appropriation and transferral of facilitation training and expertise between researchers and local groups, providing all participants with the capacity to develop more participatory water governance research-practice in the future. It also clearly oriented the direction of project outcomes because the local facilitators had the opportunity to negotiate changes to project scopes and focus questions better to fit their own interests; these changes had important ethical ramifications, as noted in the codesign section, including the de facto exclusion of certain participants and empowering of others. Specifically, one participant in case 6 who was more interested in droughts was excluded, and one of the local participants who had been flooded ended up being elected mayor because she felt that she had developed the capacity to make a difference to management in her local area.

In cases 7 and 8, an important ethical element of the coimplementation was linked to data management arrangements. The means of managing data and people's personal information evolved throughout the project because local teams of researchers and practitioners carried out individual parts of the overall project. In case 7, participants signed consent forms to take part in the more participatory parts of the research and, in some cases, were paid a small sum of money to cover their expenses. Three researchers had also decided to submit a supplementary procedural ethics approval for some of the collaborative research in a non-EU country (following the undertaking of participatory workshops). However, in case 8 , data management protocols were somewhat more ad hoc and may not have adhered to all participating countries' guidelines. Some surveying work carried out was, for example, considered to be "auditing" or preliminary scoping, meaning that ethics approval in some countries was not officially required. Such data were never published, but were used to inform later phases of codesign and coimplementation.

In case 1, researchers and practitioners were involved in coimplementation of research activities together. This included integrated knowledge making within the interdisciplinary research team and facilitated activities to develop collectively research processes and outputs with research collaborators, including policy makers, catchment managers, and farmers. By researchers engaging closely with these expert practitioners, new knowledge about the application and effectiveness of the research for improving water productivity in agriculture and environmental water management was coproduced. This coproduction process meant that new insights for practice and policy were represented and translated, not just by researchers, but by and with the people and institutions responsible for effecting practice change. This is arguably a more ethical approach to knowledge making in research-practice collaborations. As Addelson (1994:4) notes, in addressing the collectivist moral question of "How should we live?" which is at the heart of negotiating shared environmental futures, responsible action involves engaging all of those people and groups who have interests in and knowledge of a sustainable management issue.

\section{Coevaluation}

Participatory evaluation or coevaluation can be built into the design of projects and can provide the opportunity to assess progress continuously throughout the collaboration. This process requires a commitment by project participants to reflect on their own practices (or delegate this responsibility to other "external" evaluators) and is enabled through attention being given to specific evaluation activities, including those conducted jointly by social scientists with their research collaborators from within project teams. A key challenge of coevaluation is to develop evaluative criteria and measures collaboratively.

Cases 6 and 8 had rigorous coevaluation processes in which certain researchers in the project teams pushed strongly for substantial evaluation protocols to be implemented throughout the participatory components of the water governance projects. These processes were negotiated with both other researchers and local project partners, including government officials and consultants in case 8 . The processes involved participant workshop evaluations, participatory observation, participant interviews, and debriefing sessions and interviews with the project team members. Each evaluation had internal and external evaluators so that the data could be triangulated and reflected upon in comparison to other cases (see, for example, Jones et al. 2009). Such rigorous coevaluation throws up ethical challenges, including monitoring and mitigating participant discomfort, for example, due to anxiety or self-consciousness that comes through being video or audio recorded. It is also important to reflect on failed progress in collaborations without attributing blame.

In both cases 1 and 5, the participatory action research approach adopted by the social scientists in the team provided ample opportunities for reflection and sharing lessons from the research process. In case 1 , this provided the basis for a qualitative evaluation of the project by the social scientists drawn from a set of generative criteria produced by the interdisciplinary research team. However, when writing journal publications, which were left until after the main project was completed, the narrative of 
project effectiveness was produced by the social science research team rather than by all participants (i.e., no coevaluation of research data). There was no involvement in the evaluation by stakeholders outside of the research community, which arguably would have provided a more complete assessment. This was also experienced in case 5, in which journal publications were prepared after the substantive collaboration had been completed. The ethical ramification of this is that the representation of new knowledge and insights from research are not collectively negotiated within the project unless this process has been made clear from the outset with the wider stakeholders. Some project participants, but not all, manage the formal representation of research in the public domain. As noted, evaluating and representing the usefulness and relevance of research for supporting collective environmental futures should, as far as possible, involve all those research collaborators whose practices are part of achieving sustainable management of freshwater resources. Hence, coevaluation should be both embedded in research-practice codesign and involve agreement among collaborators on publicly representing the results and implications of research through copublishing and other means.

\section{DISCUSSION}

\section{Implications for ethical practice in cocreation}

In this section, we discuss the important ethical implications of collaboration across different phases of cocreation in researchpractice for sustainable freshwater management. We consider ethical practice in each of the four phases of cocreation and emphasize the key dilemmas that arise for collaborators in each phase, including when procedural ethics protocols can be introduced. We also reflect on the ways in which researcherpractitioners can ethically reflect on their own experiences of collaboration.

\section{Coinitiation: the dilemmas of engaging diverse collaborators in a flexible and emergent process}

From our experiences, key dilemmas that arise for researchers and their collaborators in the coinitiation phase of research-practice collaborations for freshwater management include: how to engage all relevant individuals and groups who wish to be engaged in the collaboration, and how to represent their different knowledge and practices in project design. These dilemmas arise because of the diversity of people and their freshwater places and the need to engage all relevant knowledge and practices in codeveloping solutions to complex problems of sustainability (Lang et al. 2012). Addressing these dilemmas relates to the need for flexibility in process design, support for participation of diverse parties, and attention to the emergent nature of collaboration. The noninvolvement of all participants in the initiation of researchpractice collaboration can be problematic because this phase can frame further activity, including the design and conduct of the research. For instance, when research-practice is framed by supply (push) or demand (pull) concepts (Dilling and Lemos 2011), it can introduce power imbalances through uneven representation of the respective interests, perspectives, and goals of collaborators.

Initiation should open up opportunities for codesign in research. Often initiation and design phases of research are conflated in practice. For example, real (co)design does not always occur until the funding arrives. It is important to recognize that a funding proposal is not necessarily a blueprint for research (Ayre et al. 2016), and research contracts and plans, depending on the cooperation of funders, can be amended, depending on the emergence of new directions in the research.

The variety of approaches to coinitiation in the cases in which we have been involved (Table 2) begs the question: When does initiation of research-practice collaborations actually happen? Some collaborations in research-practice build on past practices and relationships, so it is reasonable, in those instances, that coinitiation is a process of both expansion and innovation of these historical and contextual factors to additional participants in different times and places. Coinitiation recognizes that researchpractice collaboration can grow and change over time and should not necessarily be stabilized around the initial set of participants. In summary, ethical research-practice in the coinitiation phase of cocreation should involve attention to diversity and actions to engage all willing stakeholders, and the flexibility to negotiate research-practice aims and outcomes (for adaptive codesign).

Codesign: the dilemmas of how to manage different knowledge, interests, and goals through participative research-practice governance

The codesign phase of research-practice involves both methodological and epistemological (Ison et al. 2013) decisions about the way in which further cocreation and participatory water governance can occur. A key ethical dilemma faced by collaborators in this phase is how to manage the disparate ontological and practical commitments, which translate into an often-unarticulated set of objectives, people, and their organizations. Ethical practice in codesign involves opening up opportunities to interrogate framing (Dewulf 2007, Blackmore 2010, Ison et al. 2013, Patterson et al. 2013, Paschen and Beilin 2015) and assumptions, as well as ensuring that the needs of one group (e.g., researchers) are not given undue preference over another's (e.g., community, practitioners). Codesign needs to be coherent and manageable; thus, as highlighted in the cases provided here, the number of participants often does need to be limited. This limitation is easier when particular stakeholder groups can nominate a representative to participate, but is difficult when a large and diverse range of individual and organizational stakeholders is involved. The governance of research-practice collaborations is therefore a key part of achieving ethical codesign and includes paying attention to decision-making processes; designation of roles, including leadership roles; and resourcing to support participation in codesign through facilitation of group activities (Daniell 2012, Lang et al. 2012, Ayre and Nettle 2015). Procedural ethics approvals obtained in earlier phases may need to be amended as the form and content of the collaboration emerges through reflective codesign.

It also important in this phase to consider how ethical considerations are framed. In contexts in which participants have different cultural and personal backgrounds, commitments, and expectations, ethical practice can constitute different norms of behavior and standards for collective action. For example, in conducting freshwater management research-practice with Australian Indigenous communities, it is important to negotiate what is meant by ethical practice and determine the appropriate elements of ethical codesign. Negotiating methods that enable 
the mutual translation of Indigenous and non-Indigenous knowledge, and recognition and respect for difference, can support participants to achieve ethical research-practice. These methods include, for example, protocols for interactions between team members and agreed-upon ways of working, including how knowledge is owned, integrated, and applied (see Jackson 2006, Hoverman and Ayre 2012, Jackson et al. 2012). However, it is important to realize that creative tensions can arise in crosscultural research-practice related to whose knowledge counts and what is ethical practice (Verran 2002). Working with these tensions requires paying attention to building trust and communication between participants and being reflexive about the power dynamics between different knowledge systems. Ways to address these dynamics could include appointing an Indigenous steering committee to oversee the research-practice, codeveloping research questions, and agreeing on epistemic criteria (Addelson 1994) for good research and joint authorship of research outputs, including publications.

\section{Coimplementation: the dilemmas of doing ethical research- practice}

In the coimplementation phase of research-practice collaborations in water governance, the emphasis can shift from procedural ethics to ethical practice as consent forms are signed and filed away. Key dilemmas associated with implementation of research-practice collaborations include challenges of managing the changing relationships between researchers and their collaborators and meeting the different standards and procedures for ethics implicit in working across multiple institutions and jurisdictions. These dilemmas often arise as a result of the pressure to meet project funding timelines and milestones, which constrain the ability of collaborators to explore emergent questions and outcomes.

It is in this phase that it is important to pay attention to the roles and relationships between collaborators in freshwater management research-practice. As trust is (ideally) built, we have observed in our cases situations in which a researcher's identity might be clear upfront but can fade into the background over time, for example, when a researcher or research advisor ends up taking on a significant participatory project manager and facilitator role (e.g., cases 6, 7, and 8). Some researchers such as Ellis (2007) describe this change as a potential pitfall of long-term engagement with participants, but we can also see it as a strength of applied and reflexive research in which researchers have the option of a fluidity of role to support and broker effective research-practice in collaboration with communities and stakeholders over time.

Ethical practices in the coimplementation phase might involve seeking further verbal consent before each researchercollaborator engagement or at least reminding participants that research is taking place at regular intervals. Coresearchers could also ask individual participants to verify interview transcripts, and perhaps observations, notes, and workshop materials should also be verified as a record of the engagement if they are to be used as research data. The coproduction of research data has implications for both ownership and use of those data and for procedural ethics. As collaboration matures, practitioners can move from being relatively passive in the research to becoming active research participants and collaborators, then coresearchers, which opens up the possibility of amending ethics documents to include them formally as part of the research team. Regardless of whether formal ethics approval has been sought (it is still uncommon for many research-practice collaborations in some parts of the world, especially linked to consultancy work), researchers need to be aware in this phase of changing expectations, values, and aspirations of their partners and how to respond to ethical dilemmas that may affect the integrity of their research in order to protect and support the participants in other ways (e.g., cases 7, 8, and Daniell et al. 2009).

\section{Coevaluation: the dilemmas of measuring impact and} implementing participatory evaluation processes

Evaluation is a key aspect of justifying investment in and demonstrating the impacts of collaborations in freshwater management research-practice (Tan et al. 2008). A key dilemma is to evaluate research-practice ethically such that multiple and diverse perspectives are included in determining the value of a collaboration to improving freshwater management. The emphasis in evaluation has often been to assess against normative criteria of "best" or "good" practice in participation processes (von Korff et al. 2012) or to apply an evaluation protocol that allows comparison between participatory research practice experiences (e.g., Jones et al. 2009, Daniell 2012, Hassenforder et al. 2015, 2016). Such approaches can be useful for satisfying policy and funding stakeholders or can have some value for understanding and elaborating context-specific learning and practice-change outcomes from participation of diverse individuals and their organizations.

However, the key to representing the diverse knowledge and practice outcomes for collaborators in freshwater management is to engage (at least ideally) all participants in defining evaluation criteria and metrics for those criteria (Ayre and Nettle 2015). Of course, this may be impossible in some collaborative projects with large numbers of participants who are not interested in the research component of the collaboration. However, in either case, regardless of whether the coevaluation is designed and implemented by just a few or many, it is important to build coevaluation into the codesign phase of collaborations to guide participants in critical reflection on success criteria throughout the life of a collaborative project. We thus consider that procedural ethics approvals should cover the coevaluation phase of the collaboration, including the collection, management, and representation of evaluation data. However, in collaborations in which action research (Carr and Kemmis 1986) includes the generative and ongoing reflection of participants together on progress, this can be challenging. In these cases, it may be necessary to gain amendments to procedural ethics as the collaboration proceeds. More generally, this highlights a current weakness in many procedural ethics processes, which do not readily accommodate the iterative cycles of reflection, planning, and action in participatory research-practice approaches.

Ethical conduct in collaborations is also implicated in the assemblage and use of project data for communication and dissemination of project findings through various media and formats. The coevaluation phase should include agreed-upon approaches and protocols for ex-post analysis of data and checking and validation of project findings. In practice, because the production of published and other materials often happens beyond the (formal) end of projects, participants may need to 
agree to continue to collaborate through both remote and faceto-face interaction to ensure all perspectives are properly represented and findings are consistent with shared learning and outcomes. This is particularly important when working with diverse knowledge and practice communities such as in crosscultural collaborations, including with Indigenous communities (see Kovach 2015).

\section{Procedural ethics considerations}

Given the varying nature of collaboration across different phases of research-practice engagement, the role of procedural ethics is worth considering. For instance, it may not be necessary to seek ethics approval at the coinitiation phase. Instead, institutional arrangements such as an $\mathrm{MoU}$ or project proposal may provide useful ways of considering ethical practices for further phases of engagement. At a minimum, approval from an ethics committee should be sought at the codesign phase if it becomes apparent from the methodology that data will be collected from participants. If the nature of the engagement changes during the coimplementation or coevaluation phases, for instance, if additional researchers join the collaboration, then ethics approval should be sought or amended and consideration given to seeking consent to use prior project management materials as data.

In some research-practice situations, potential collaborators may need to spend some time together, building trust and negotiating the relevant terms, processes, and outcomes of the collaboration. For example, in working with Indigenous communities and local or policy-maker communities in different places around the world, it may be important for researchers to demonstrate their commitment to mutually beneficial work by spending time building relationships with these coresearchers before formal funding proposals and associated ethics protocols are either developed or approved. This dilemma can apply, however, to any group and particularly other potentially at-risk groups. Also, involving community members in initiation can be difficult because they do not always have the same institutional support to participate in scoping activities as do researchers and government employees. Project proponents should therefore consider providing financial or other support to enable community members to participate in coinitiation processes. We also note that sometimes notes and observations are made by researchers before the research codesign and coimplementation phases begin but that might later be drawn on for research purposes. This means that retrospective ethics approvals may have to be sought, and perhaps more importantly, retrospective consent from the people involved in the research, regardless of whether ethics approval has been sought or not.

At this point, we think that it is worth highlighting that just because a project has received ethics approval, what will be undertaken in it will not necessarily constitute ethical practice from the points of view of all those involved and any external observers. Also, as we have previously noted, agreed-upon ethical protocols and practices may not be followed, but rather just filed away. On the other hand, it is also possible to act ethically, putting a great deal of effort into developing ethical and mutually acceptable research-practice, without formal procedural ethics approval, even if this may create issues for publishing in international journals managed in some western countries. Then there are many more grey areas in between that could be open to debate. We note, in particular, the dilemma of commentators or consultants who are not officially governed by ethics approvals. For instance, is procedural ethics needed to cover a public event where media is present to write stories or publish videos, tweets, or stories on what they have seen; or is procedural ethics needed to write a consultancy report that may be made public by its financer? Could this coverage then be cited in research? There are examples where consent is considered to be given unless it is expressly noted it is not given, for instance, when the Chatham House Rule is invoked to enable sharing of information without identifying individuals. Some countries (e.g., Vanuatu, Fiji) and communities (e.g., in Indigenous Australia) also require researchers to have research permits to work on their lands, so to what extent is it reasonable or should it be expected that researchers hold multiple approvals, especially in cases in which the requirements may clash? And what should researchers do when there are clashes between principles in an ethics standard or between research ethics and other codes of conduct that govern researchers and their partners' conduct (e.g., as registered professionals such as engineers and lawyers or as public servants)? Here, as Daniell et al. (2009) state, it is often necessary for the ethics applied in participatory research-practice to be codeveloped, i.e., developing the rules and norms under which the relationships, practices, and research ought to take place. Ideally, this collective development of mutually agreed-upon ethics should begin in the coinitiation stage and be revisited and renegotiated as the process evolves and new dilemmas not originally envisaged emerge. In this way, the role of procedural ethics committees may move "beyond critique to participation" (Batterbury 2014).

\section{Reflecting on experiences of collaboration and the future of ethical research-practice}

Researchers and practitioners sometimes choose to synthesize and reflect on their individual or collective experiences beyond the completion of particular projects or collaborations, which itself raises questions of ethical practice. In particular, how can reflective practices ensure that identities are protected and that data from other participants in those experiences are not used without their consent? This dilemma has been approached in different ways. For example, Patterson et al. (2013) engaged in autoethnographic inquiry (Ellis and Bochner 2000) into their experiences in transdisciplinary water governance research using self-directed questions that positioned themselves as both researchers and subjects, enabling them to protect their own privacy. Steyaert and Jiggins (2007:582) documented an approach of continually reflecting on "the practices of research and the ethics of being a researcher" and generated a synthesis through a community of practice (Wenger 1998) involving researchers and case-study participants from a large, multicountry program of water governance research-practice engagement. Similar communities of practice have since been formed to provide safe spaces not only for researchers but also for researchers and practitioners of participatory practice to "practice their practice" through facilitation trials and simulation of participatory processes in a range of natural resources management domains, including water management (Dionnet et al. 2013). Through simulation, often ethical dilemmas will appear before they do in the field, allowing participants to reflect on and hopefully develop strategies for addressing them before they arise in reality. 
Other important factors that we have not elaborated upon here but that nevertheless warrant consideration in developing ethical practice in research-practice engagements include the influence of funders on research ethics (Bell and Bryman 2007), the management of turnover of research and practitioners in longer research collaborations, and the role of leaders in directing or supporting ethical research-practice. Such issues arose, for example, in the negotiated research-practice and comanagement interactions developed between the New South Wales Government (Australia) Aboriginal Water Initiative and Indigenous communities. Despite working hard to build trust and negotiate protocols for interaction and data management to manage water and its associated values, as well as to build cultural awareness in the government, funding was later removed, and much of the good will and ethical research-practice was put into peril (see Taylor et al. 2016).

Although inhabiting a grey area in the formal arena of ethics approvals, we are of the opinion that more reflection and comparison of ethical dilemmas and how ethics can be made to function in research-practice, such as that undertaken here, is good (see Guillemin and Gillam 2004). Many young researchers are afraid to engage in participatory research or with certain communities because of the ethical overheads. We do not think that this is a positive side effect of the bureaucratization associated with ethics approvals. Instead, it is important that current processes be adapted that provide support to researchers embarking on challenging and important participatory water management research-practice. This could mean in-person or virtual (e.g., by video- or teleconference) sounding board panels convened to check at regular intervals on research-practice collaborations being developed. The process could function more as a community of ethical practice that people join through registration of the cooperation and could provide an arena for reflection and problem solving, rather than a potentially feared or punitive exercise that often leads to a rejection of some of the more innovative and collaborative research-practice activities.

\section{CONCLUSION}

Addressing the new United Nations sustainable development goals (United Nations 2015) necessitates implementation of sustainable resource management, including freshwater management, across a range of scales from international and national to regional and local, along with cocreation of new sustainable management practices between scientists, communities, and policy makers (Griggs et al. 2014). Cocreating such practices involves managing the diversity, complexity, and uncertainty inherent in freshwater management and requires engaging the full range of water stakeholders in decision making and implementation of actions. These challenges compel us to ask questions of ourselves as researcher-practitioners such as: Who benefits and how from such efforts? and What kinds of future worlds do we want to create and live in together? These are necessarily ethical dilemmas and must be addressed to engender sustainable development in freshwater management.

From our experiences and the cases we present here, we propose that ethical cocreation is critical to the development of researchpractice collaborations that properly account for the multiple knowledge, interests, and practices of water users and their institutions for improved outcomes in freshwater management.
Cocreation represents an emerging approach to participation and collaboration in freshwater management research-practice and can be understood to constitute four interlinked and iterative phases: coinitiation, codesign, coimplementation, and coevaluation. For freshwater researchers and managers and their collaborators, paying attention to these phases and the ethical dilemmas that arise within each phase will support the cocreation of more effective and ethical research-practice through: sensitizing collaborators to the need for reflexivity in research-practice, proposing action research codesign as a method for managing emergent questions and outcomes, and supporting more equitable outcomes for collaborators through an emphasis on coevaluation and collaborative articulation of the links between research outputs and practice outcomes. Because cocreation of researchpractice is still a relatively new paradigm and is very foreign to many research communities based on disciplinary expertise and methodologies developed and honed over many decades or centuries, research infrastructure, including ethics approvals structures, is often not set up to support cocreation adequately. We consider that more thinking and action are required to develop appropriate, and indeed, participatory, procedural ethics support mechanisms that will encourage a transition to more effective ethical research-practice collaboration in freshwater management around the world.

Responses to this article can be read online at: http://www.ecologyandsociety.org/issues/responses. $\mathrm{php} / 9822$

\begin{abstract}
Acknowledgments:
We acknowledge our collaborators over many different projects who have worked with us to meet the challenges of engaging diverse knowledge communities in developing strategies for sustainably managing freshwater resources. We also acknowledge the Peter Cullen Trust, through which many fruitful collaborations have arisen, including this one.
\end{abstract}

\section{LITERATURE CITED}

Addelson, K. P. 1994. Moral passages: toward a collectivist moral theory. Routledge, New York, New York, USA.

Allen, W., A. Fenemor, M. Kilvington, G. Harmsworth, R. G. Young, N. Deans, C. Horn, C. Phillips, O. Montes de Oca, J. Ataria, and R. Smith. 2011. Building collaboration and learning in integrated catchment management: the importance of social process and multiple engagement approaches. New Zealand Journal of Marine and Freshwater Research 45(3):525-539. http:// dx.doi.org/10.1080/00288330.2011.592197

Armitage, D., F. Berkes, A. Dale, E. Kocho-Schellenberg, and E. Patton. 2011. Co-management and the co-production of knowledge: learning to adapt in Canada's Arctic. Global Environmental Change 21(3):995-1004. https://doi.org/10.1016/j. gloenvcha.2011.04.006

Ayre, M., and R. Nettle. 2015. Doing integration in catchment management research: insights into a dynamic learning process. Environmental Science and Policy 47:18-31. https://doi. org/10.1016/j.envsci.2014.10.011 
Ayre, M. L., and R. A. Nettle. 2017. Enacting resilience for adaptive water governance: a case study of irrigation modernization in an Australian catchment. Ecology and Society 22(3):1. https://doi.org/10.5751/ES-09256-220301

Ayre, M., R. Nettle, M. Erazo Bobenreith, and L. Klerkx. 2016. Doing water research differently for innovation in regional water productivity in Australia. Australian Journal of Water Resources 20(1):39-52. https://doi.org/10.1080/13241583.2016.1162763

Barreteau, O., P. W. G. Bots, and K. A. Daniell. 2010. A framework for clarifying "participation" in participatory research to prevent its rejection for the wrong reasons. Ecology and Society 15(2):1. http://www.ecologyandsociety.org/vol15/iss2/art1/

Batterbury, S. 2014. Human research ethics committees: beyond critique to participation. Australian Journal of Anthropology 25 (3):385-386. http://dx.doi.org/10.1111/taja.12109 6

Becker, H. S. 1986. Doing things together: selected papers. Northwestern University Press, Evanston, Illinois, USA.

Bell, E., and A. Bryman. 2007. The ethics of management research: an exploratory content analysis. British Journal of Management 18(1):63-77. http://dx.doi.org/10.1111/

j.1467-8551.2006.00487.x

Berkes, F. 2009. Evolution of co-management: role of knowledge generation, bridging organizations and social learning. Journal of Environmental Management 90(5):1692-1702. http://dx.doi. org/10.1016/j.jenvman.2008.12.001

Blackmore, C., editor. 2010. Social learning systems and communities of practice. Springer, London, UK. http://dx.doi. org/10.1007/978-1-84996-133-2

Blackmore, C., R. Ison, and J. Jiggins. 2007. Social learning: an alternative policy instrument for managing in the context of Europe's water. Environmental Science and Policy 10(6):493-498. http://dx.doi.org/10.1016/j.envsci.2007.04.003

Bosomworth, K., P. Leith, A. Harwood, and P. J. Wallis. 2017. What's the problem in adaptation pathways planning? The potential of a diagnostic problem-structuring approach. Environmental Science and Policy 76:23-28. http://dx.doi. org/10.1016/j.envsci.2017.06.007

Brugnach, M., and H. Ingram. 2012. Ambiguity: the challenge of knowing and deciding together. Environmental Science and Policy. 15(1):60-71. http://dx.doi.org/10.1016/j.envsci.2011.10.005

Camkin, J. 2016. Sharing stakeholder knowledge across water management boundaries and interfaces: experiences from Australian and New Zealand 'HELP' basins. Australasian Journal of Water Resources 20(1):53-64. http://dx.doi.org/10.1080/1324$\underline{1583.2016 .1211471}$

Carr, W., and S. Kemmis. 1986. Becoming critical: education, knowledge and action research. RoutledgeFarmer, London, UK.

Collins, K., J. Colvin, and R. Ison. 2009. Building 'learning catchments' for integrated catchment managing: designing learning systems based on experiences in the UK and South Africa. Water Science and Technology 59(4):687-693. http://dx. doi.org/10.2166/wst.2009.889
Creighton, J. L. 2005. The public participation handbook: making better decisions through citizen involvement. Jossey-Bass, San Francisco, California, USA.

Daniell, K. A. 2016. Developing and improving bi-regional dialogue between Europe and the Pacific in science, technology and innovation. Deliverable 3.4 for the PACE-Net Plus EU Project FP7. Australian National University, Canberra, Australia.

Daniell, K. A. 2012. Co-engineering and participatory water management: organizational challenges for water governance. Cambridge University Press, Cambridge, UK. http://dx.doi. org/10.1017/CBO9780511998072

Daniell, K. A., I. White, N. Ferrand, I. S. Ribarova, P. Coad, J.E. Rougier, M. Hare, N. A. Jones, A. Popova, D. Rollin, P. Perez, and S. Burn. 2010. Co-engineering participatory water management processes: theory and insights from Australian and Bulgarian interventions. Ecology and Society 15(4):11. http://dx. doi.org/10.5751/ES-03567-150411

Daniell, K. A., I. White, and D. Rollin. 2009. Ethics and participatory water planning. Pages 1476-1487 in Proceedings of H2009 32nd Hydrology and Water Resources Symposium, Newcastle, 2009. Engineers Australia, Newcastle, Australia.

De Vries, R., D. A. DeBruin, and A. Goodgame. 2004. Ethics review of social, behavioral, and economic research: where should we go from here? Ethics and Behavior 14(4):351-368. https://doi. org/10.1207/s15327019eb1404 6

Dewulf, A., G. François, C. Pahl-Wostl, and T. Taillieu. 2007. A framing approach to cross-disciplinary research collaboration: experiences from a large-scale research project on adaptive water management. Ecology and Society 12(2):14. http://dx.doi. org/10.5751/ES-02142-120214

Dilling, L., and M. C. Lemos. 2011. Creating usable science: opportunities and constraints for climate knowledge use and their implications for science policy. Global Environmental Change 21 (2):680-689. http://dx.doi.org/10.1016/j.gloenvcha.2010.11.006

Dionnet, M., K. A. Daniell, A. Imache, Y. von Korff, S. Bouarfa, P. Garin, J.-Y. Jamin, D. Rollin, and J.-E. Rougier. 2013. Improving participatory processes through collective simulation: use of a community of practice. Ecology and Society 18(1):36. http://dx.doi.org/10.5751/ES-05244-180136

Doorn, N. 2013. Water and justice: towards an ethics of water governance. Public Reason 5(1):97-114. [online] URL: http:// www.publicreason.ro/articol/83

Ellis, C. 2007. Telling secrets, revealing lives: relational ethics in research with intimate others. Qualitative Inquiry 13(1):3-29. http://dx.doi.org/10.1177/1077800406294947

Ellis, C. S., and A. Bochner. 2000. Autoethnography, personal narrative, reflexivity: researcher as subject. Pages 733-768 in $\mathrm{N}$. K. Denzin and Y. S. Lincoln, editors. Handbook of qualitative research. Second edition. Sage, Thousand Oaks, California, USA.

European Parliament. 1995. Directive 95/46/EC of the European Parliament and of the Council of 24 October 1995 on the protection of individuals with regard to the processing of personal data and on 
the free movement of such data. European Commission, Brussels, Belgium. [online] URL: http://data.europa.eu/eli/dir/1995/46/oj

Farms, Rivers and Markets Project. 2012. Farms, rivers and markets: doing more with less water: overview report. Farms, Rivers and Markets Project, Victoria, Australia. http://dx.doi. org/10.13140/RG.2.1.2122.9920

Farquharson, R. J., J. W. Freebairn, J. A. Webb, M. J. Stewardson, and T. Ramilan. 2017. An economic framework for sharing water within a river catchment. Water Economics and Policy 3 (3):1650039. http://dx.doi.org/10.1142/S2382624X16500399

Fenemor, A., C. Phillips, W. Allen, R. G. Young, G. Harmsworth, B. Bowden, L. Basher, P. A. Gillespie, M. Kilvington, R. DaviesColley, J. Dymond, A. Cole, G. Lauder, T. Davie, R. Smith, S. Markham, N. Deans, B. Stuart, M. Atkinson, and A. Collins. 2011. Integrated catchment management-interweaving social process and science knowledge. New Zealand Journal of Marine and Freshwater Research 45(3):313-331. http://dx.doi. org/10.1080/00288330.2011.593529

Forsyth, M. 2014. Research permit schemes in Pacific island countries. In Brief 2014/55. Australian National University, Canberra, Australia. [online] URL: http://bellschool.anu.edu.au/ sites/default/files/publications/attachments/2015-12/IB-2014-55-Forsythresearch permit schemes-revised 0.pdf

Griggs, D., M. Stafford Smith, J. Rockström, M. C. Öhman, O. Gaffney, G. Glaser, N. Kanie, I. Noble, W. Steffen, and P. Shyamsundar. 2014. An integrated framework for sustainable development goals. Ecology and Society 19(4):49. http://dx.doi. org/10.5751/ES-07082-190449

Groenfeldt, D. 2013. Water ethics: a values approach to solving the water crisis. Earthscan, Abingdon, UK.

Groenfeldt, D., and J. J. Schmidt. 2013. Ethics and water governance. Ecology and Society 18(1):14. http://dx.doi. org/10.5751/ES-04629-180114

Guillemin, M., and L. Gillam. 2004. Ethics, reflexivity, and "ethically important moments" in research. Qualitative Inquiry 10(2):261-280. http://dx.doi.org/10.1177/1077800403262360

Hare, M. 2011. Forms of participatory modelling and its potential for widespread adoption in the water sector. Environmental Policy and Governance 21(6):386-402. http://dx.doi.org/10.1002/eet.590

Hassenforder, E., J. Pittock, O. Barreteau, K. A. Daniell, and N. Ferrand. 2016. The MEPPP framework: a framework for monitoring and evaluating participatory planning processes. Environmental Management 57(1):79-96. http://dx.doi.org/10.1007/ $\underline{\mathrm{s} 00267-015-0599-5}$

Hassenforder, E., A. Smajgl, and J. Ward. 2015. Towards understanding participatory processes: framework, application and results. Journal of Environmental Management 157:84-95. https://doi.org/10.1016/j.jenvman.2015.04.012

Heron, J., and P. Reason. 2001. The practice of co-operative inquiry: research with rather than on people. Pages 179-188 in $\mathrm{P}$. Reason and H. Bradbury, editors. Handbook of action research: participative inquiry and practice. Sage, London, UK.

Hoverman, S., and M. Ayre. 2012. Methods and approaches to support Indigenous water planning: an example from the Tiwi
Islands, Northern Territory, Australia. Journal of Hydrology 474:47-56. https://doi.org/10.1016/j.jhydrol.2012.03.005

Ison, R. 2010. Systems practice: how to act in a climate-change world. Springer, London, UK.

Ison, R., C. Blackmore, and B. L. Iaquinto. 2013. Towards systemic and adaptive governance: exploring the revealing and concealing aspects of contemporary social-learning metaphors. Ecological Economics 87:34-42. http://dx.doi.org/10.1016/j. ecolecon.2012.12.016

Ison, R. L., K. B. Collins, and P. J. Wallis. 2015. Institutionalising social learning: towards systemic and adaptive governance. Environmental Science and Policy 53(B):105-117. http://dx.doi. org/10.1016/j.envsci.2014.11.002

Ison, R., N. Röling, and D. Watson. 2007. Challenges to science and society in the sustainable management and use of water: investigating the role of social learning. Environmental Science and Policy 10(6):499-511. http://dx.doi.org/10.1016/j.envsci.2007.02.008

Ison, R. L., P. Steyaert, P. P. Roggero, B. Hubert, and J. Jiggins, editors. 2004. The SLIM (social learning for the integrated management and sustainable use of water at catchment scale) final report. European Union Fifth Framework Programme, European Commission, Brussels, Belgium. [online] URL: http://oro.open. ac.uk/2839/

Jackson, S. 2006. Compartmentalising culture: the articulation and consideration of Indigenous values in water resource management. Australian Geographer 37(1):19-31. http://dx.doi. org/10.1080/00049180500511947

Jackson, S., P.-L. Tan, C. Mooney, S. Hoverman, and I. White. 2012. Principles and guidelines for good practice in Indigenous engagement in water planning. Journal of Hydrology 474:57-65. http://dx.doi.org/10.1016/j.jhydrol.2011.12.015

Jones, N. A., P. Perez, T. G. Measham, G. J. Kelly, P. d'Aquino, K. A. Daniell, A. Dray, and N. Ferrand. 2009. Evaluating participatory modeling: developing a framework for cross-case analysis. Environmental Management 44(6):1180. https://doi. org/10.1007/s00267-009-9391-8

Kilvington, M., W. Allen, and A. Fenemor. 2011a. Three frameworks to understand and manage social processes for integrated catchment management. New Zealand Journal Marine and Freshwater Research 45(3):541-555. https://doi. org/10.1080/00288330.2011.593182

Kilvington, M., M. Atkinson, and A. Fenemor. 2011b. Creative platforms for social learning in ICM: the Watershed Talk project. New Zealand Journal Marine and Freshwater Research 45 (3):557-571. https://doi.org/10.1080/00288330.2011.593528

Kovach, M. 2015. Emerging from the margins: Indigenous methodologies. Pages 43-64 in S. Strega and L. Brown, editors. Research as resistance: revisiting critical, indigenous, and antioppressive approaches. Second edition. Canadian Scholars' Press Toronto, Canada.

Lach, D., S. Rayner, and H. Ingram. 2005. Taming the waters: strategies to domesticate the wicked problems of water resource management. International Journal of Water 3(1):1-17. http://dx. doi.org/10.1504/IJW.2005.007156 
Lang, D. J., A. Wiek, M. Bergmann, M. Stauffacher, P. Martens, P. Moll, M. Swilling, and C. J. Thomas. 2012. Transdisciplinary research in sustainability science: practice, principles, and challenges. Sustainability Science 7(1):25-43. http://dx.doi. org/10.1007/s11625-011-0149-X

Latour, B. 1987. Science in action: how to follow scientists and engineers through society. Harvard University Press, Cambridge, Massachusetts, USA.

Lukasiewicz, A., S. Dovers, L. Robin, J. McKay, S. Schilizzi, and S. Graham, editors. 2017. Natural resources and environmental justice: Australian perspectives. CSIRO Publishing, Canberra, Australia.

Mackay, M., C. Allan, R. Colliver, and J. Howard. 2014. Systems approaches enable improved collaboration in two regional Australian natural resource governance situations. International Journal of Systems and Society 1(2):1. http://dx.doi.org/10.4018/ ijss. 2014070101

Mackenzie, J., P.-L. Tan, S. Hoverman, and C. Baldwin. 2012. The value and limitations of participatory action research methodology. Journal of Hydrology 474:11-21. http://dx.doi. org/10.1016/j.jhydrol.2012.09.008

Midgley, G. 2000. Systemic intervention: philosophy, methodology, and practice. Kluwer/Plenum, New York, New York, USA.

Mostert, E., C. Pahl-Wostl, Y. Rees, B. Searle, D. Tàbara, and J. Tippett. 2007. Social learning in European river-basin management: barriers and fostering mechanisms from 10 river basins. Ecology and Society 12(1):19. https://www.ecologyandsociety. org/vol12/iss1/art19/

Orlove, B., and S. C. Caton. 2010. Water sustainability: anthropological approaches and prospects. Annual Review of Anthropology 39:401-415. http://dx.doi.org/10.1146/annurev. anthro.012809.105045

Pahl-Wostl, C., and N. Kranz. 2010. Water governance in times of change. Environmental Science and Policy 13(7):567-570. http:// dx.doi.org/10.1016/j.envsci.2010.09.004

Paschen, J.-A., and R. Beilin. 2015. 'Avoiding the certainty trap': a research programme for the policy-practice interface. Environment and Planning C: Government and Policy 33 (6):1394-1411. https://doi.org/10.1068/c13321

Patterson, J. J., A. Lukasiewicz, P. J. Wallis, N. Rubenstein, B. Coffey, E. Gachenga, and A. J. J. Lynch. 2013. Tapping fresh currents: fostering early-career researchers in transdisciplinary water governance research. Water Alternatives 6(2):293-312. [online] URL: http://www.water-alternatives.org/index.php/ alldoc/articles/vol6/v6issue2/217-a6-2-14

Patton, M. Q. 2011. Developmental evaluation: applying complexity concepts to enhance innovation and use. Guilford Press, New York, New York, USA.

Plummer, R., B. Crona, D. R. Armitage, P. Olsson, M. Tengö, and O. Yudina. 2012. Adaptive comanagement: a systematic review and analysis. Ecology and Society 17(3):11. http://dx.doi. org/10.5751/ES-04952-170311

Pohl, C., S. Rist, A. Zimmermann, P. Fry, G. S. Gurung, F. Schneider, C. I. Speranza, B. Kiteme, S. Boillat, E. Serrano, G.
Hirsch Hadorn, and U. Wiesmann. 2010. Researchers' roles in knowledge co-production: experience from sustainability research in Kenya, Switzerland, Bolivia and Nepal. Science and Public Policy 37(4):267-281. http://dx.doi.org/10.3152/030234210X496628

Pradhan, R., and R. Meinzen-Dick. 2003. Which rights are right? Water rights, culture, and underlying values. Water Nepal 10 (1):37-61. http://dx.doi.org/10.3126/wn.v10i1.93

Ribarova, I., D. P. Assimacopoulos, P. Jeffrey, K. A. Daniell, D. Inman, L. S. Vamvakeridou-Lyroudia, T. Melin, P. Kalinkov, N. Ferrand, and K. Tarnaki. 2011. Research-supported participatory planning for water stress mitigation. Journal of Environmental Planning and Management 54(2):283-300. https:// doi.org/10.1080/09640568.2010.506074

Rubenstein, N., P. J. Wallis, R. L. Ison, and L. Godden. 2016. Critical reflections on building a community of conversation about water governance in Australia. Water Alternatives 9 (1):81-98. [online] URL: http://www.water-alternatives.org/ index.php/alldoc/articles/vo19/v9issue1/305-a9-1-4

Schmidt, J. J. 2014. Water management and the procedural turn: norms and transitions in Alberta. Water Resources Management 28(4):1127-1141. http://dx.doi.org/10.1007/s11269-014-0544-Z

Schmidt, J. J., and C. Z. Peppard. 2014. Water ethics on a humandominated planet: rationality, context and values in global governance. WIRES Water 1(6):533-547. http://dx.doi.org/10.1002/ wat2.1043

Schön, D. A. 1984. The reflective practitioner: how professionals think in action. Basic Books, New York, New York, USA.

Seligman, C., G. J. Syme, and R. Gilchrist. 1994. The role of values and ethical principles in judgments of environmental dilemmas. Journal of Social Issues 50(3):105-119. http://dx.doi.org/10.1111/ j.1540-4560.1994.tb02422.x

Shove, E., and G. Walker. 2010. Governing transitions in the sustainability of everyday life. Research Policy 39(4):471-476. http://dx.doi.org/10.1016/j.respol.2010.01.019

Sofoulis, Z. 2013. Water systems adaptation: an Australian cultural researcher's perspective. Water Resources Management 27(4):949-951. http://dx.doi.org/10.1007/s11269-012-0224-9

Steyaert, P., and J. Jiggins. 2007. Governance of complex environmental situations through social learning: a synthesis of SLIM's lessons for research, policy and practice. Environmental Science and Policy 10(6):575-586. http://dx.doi.org/10.1016/j. envsci.2007.01.011

Syme, G. J., N. B. Porter, U. Goeft, and E. A. Kington. 2008. Integrating social well being into assessments of water policy: meeting the challenge for decision makers. Water Policy 10 (4):323-343. http://dx.doi.org/10.2166/wp.2008.152

Syme, G. J., and B. S. Sadler. 1994. Evaluation of public involvement in water resources planning: a researcherpractitioner dialogue. Evaluation Review 18:523-542. https://doi. org/10.1177/0193841X9401800501

Tan, P.-L., S. Jackson, P. Oliver, J. Mackenzie, W. Proctor, and M. Ayre. 2008. Collaborative water planning: context and practice. Literature review. Volume 1. Land and Water Australia, Canberra, 
Australia. [online] URL: http://www.nespnorthern.edu.au/wpcontent/uploads/2016/07/collaborativewaterplanningcontext.pdf

Taylor, K. S., B. J. Moggridge, and A. Poelina. 2016. Australian Indigenous water policy and the impacts of the ever-changing political cycle. Australasian Journal of Water Resources 20 (2):132-147.

United Nations. 2015. Transforming our world: the 2030 agenda for sustainable development. Resolution adopted by the General Assembly on 25 September, 70th session, agenda items 15 and 116. A/RES/70/1. United Nations, Rome, Italy. [online] URL: http:// www.un.org/ga/search/view_doc.asp?symbol=A/RES/70/1\&Lang= $\underline{E}$

Verran, H. 2002. A postcolonial moment in science studies: alternative firing regimes of environmental scientists and aboriginal landowners. Social Studies of Science 32(5-6):729-762. http://dx.doi.org/10.1177/030631270203200506

von Korff, Y., P. d'Aquino, K. A. Daniell, and R. Bijlsma. 2010. Designing participation processes for water management and beyond. Ecology and Society 15(3):1. http://www.ecologyandsociety. org/vol15/iss3/art1/

von Korff, Y., K. A. Daniell, S. Moellenkamp, P. Bots, and R. M. Bijlsma. 2012. Implementing participatory water management: recent advances in theory, practice, and evaluation. Ecology and Society 17(1):30. http://dx.doi.org/10.5751/ES-04733-170130

Wallis, P. J., K. Bosomworth, A. Harwood, and P. Leith. 2017. Charting the emergence of a "knowing system" for climate change adaptation in Australian regional natural resource management. Geoforum 84:42-50. http://dx.doi.org/10.1016/j.geoforum.2017.06.002

Wallis, P. J., L. C. Godden, R. L. Ison, and N. Rubenstein. 2012. Building a community of conversation about water governance in Australia. Pages 665-672 in K. A. Daniell, editor. Water and climate: policy implementation challenges; proceedings of the 2 nd Practical Responses to Climate Change Conference, 1-3 May, Canberra. Engineers Australia, Barton, Australia.

Wenger, E. 1998. Communities of practice: learning, meaning, and identity. Cambridge University Press, Cambridge, UK.

White, I., K. A. Daniell, G. Ruecker, and R. Robinson. 2012. Climate change and freshwater in the Pacific: adapting to global change in the freshwater and sanitation sector: better water, better life, better world. Policy Brief 1. Report from the PACE-Net Key Stakeholder Conference, Brussels, 20-23 July 2012. PACE-Net, FP7, Europe, 27. [online] URL: http://brussels-conference-2012. pacenet.eu.s3-website-eu-west-1.amazonaws.com/sites/default/files/ PACE-NET Policy Briefno1 Water.pdf

Whiteley, J. M., H. Ingram, and R. W. Perry, editors. 2008. Water, place, and equity. MIT Press, Cambridge, Massachusetts, USA. http://dx.doi.org/10.7551/mitpress/9780262232715.001.0001

Wiering, M., J. Verwijmeren, K. Lulofs, and C. Feld. 2010. Experiences in regional cross border co-operation in river management. Comparing three cases at the Dutch-German border. Water Resources Management 24(11):2647-2672. https:// doi.org/10.1007/s11269-009-9572-5
Wyborn, C. A. 2015. Connecting knowledge with action through coproductive capacities: adaptive governance and connectivity conservation. Ecology and Society 20(1):11. http://dx.doi. org/10.5751/ES-06510-200111 